\title{
Histoarchitecture of Schistosomal Granuloma Development and Involution: Morphogenetic and Biomechanical Approaches
}

\author{
Henrique L Lenzi ${ }^{+}$, Eitan Kimmel*/ ${ }^{++}$, Helio Schechtman**, Marcelo Pelajo- \\ Machado $^{+++}$, Waldemiro S Romanha, Ronaldo G Pacheco***, \\ Mario Mariano****, Jane A Lenzi
}

\begin{abstract}
Departamento de Patologia, Instituto Oswaldo Cruz, Av. Brasil 4365, 21045-900 Rio de Janeiro, RJ, Brasil *Department of Agricultural Engineering, Technion-Israel Institute of Technology, Technion City, Haifa 32000 , Israel **Programa de Computação Científica, Presidência, Fiocruz, Av. Brasil 4365, 21045-900 Rio de Janeiro, RJ, Brasil ***Departamento de Medicina Geral, Hospital Universitário Gaffrée e Guinle, Universidade do Rio de Janeiro, Rua Mariz e Barros 775, 20270-004 Rio de Janeiro, RJ, Brasil **** Departamento de Imunologia, Instituto de Ciências Biomédicas, Universidade de São Paulo, Av. Prof. Lineu Prestes 2415, 05508-900

São Paulo, SP, Brasil
\end{abstract}

The authors present morphogenetic and biomechanical approaches on the concept of the Schistosoma mansoni granulomas, considering them as organoid structures that depend on cellular adhesion and sorting, forming rearrangement into hierarchical concentric layers, creating tension-dependent structures, aiming to acquire round form, since this is the minimal energy form, in which opposing forces pull in equally from all directions and are in balance. From the morphogenetic point of view, the granulomas function as little organs, presenting maturative and involutional stages in their development with final disappearance (pre-granulomatous stages, subdivided in: weakly and/or initial reactive and exudative; granulomatous stages: exudative-productive, productive and involutional). A model for the development of granulomas was suggested, according to the following stages: encapsulating, focal histolysis, fiber production, orientation and compacting and involution and desintegration. The authors concluded that schistosomal granuloma is not a tangled web of individual cells and fibers, but an organized structure composed by host and parasite components, which is not formed to attack the miracidia, but functions as an hybrid interface between two different phylogenetic beings.

Key words: Schistosoma mansoni - granuloma - biomechanics - fibrosis - extracellular matrix - laser confocal microscopy

There are various definitions for the term granuloma, creating a nosological chaos, which combines etiologic, mechanistic and anatomical approaches (Epstein 1983). Some of these definitions, as well as the classification and pathogenesis of granulomas, have been discussed in reviews by Adams (1976, 1983), Warren (1976), Epstein (1977), Boros (1978), Williams and Williams (1983), Hirsh and Johnson (1984), De Britto and Franco (1994) and Mariano (1995). Most of them stress the etiology, or the main cellular component, or the participation or not of the immune system,

\footnotetext{
${ }^{+}$Corresponding author. Fax: $+55-21-598.4466$. E-mail: hlenzi@gene.dbbm.fiocruz.br

${ }^{++} \mathrm{CNPq}$ Visiting Professor

${ }^{+++}$CAPES fellowship

Received 4 May 1998

Accepted 31 August 1998
}

or the differences in terms of the relative number of the new macrophages entering the granuloma (low and high turnover granulomas), or the participation or not of tissue injury. Although the concept of the granuloma has been dogged by many confusions, there are some universal accepted convergences, or diagnostic criteria such as: (i) granuloma is a focal chronic inflammatory reaction; (ii) it is characterized by the collection of cells of the "mononuclear phagocyte series", with or without the addition of other cell types (Turk 1992); (iii) the collection of mononuclear cells is compact and organized (Adams 1983); and (iv) epithelioid cells define the typical granulomatous lesion (Mariano 1995).

In this study we are presenting a morphogenetic and biomechanical approach on the concept of the granulomas, considering them as organoid structures that depend on cellular adhesion and sorting, forming rearrangement into hierarchical concentric layers, creating tension-dependent struc- 
tures, aiming to acquire round form, since this is the minimal energy form, in which opposing forces pull in equally from all directions and are in balance (Ingber 1993). From the morphogenetic point of view, the granulomas function as little organs, presenting maturative and involutional stages in their development, with final disappearance. The dynamism of the granulomatous process depends on the characteristic of the etiologic agent, which could be intracellular, intra and extracellular or extracellular (Lenzi et al. 1991). Schistosomal granuloma is the best example of the late category and is the subject of this paper.

\section{PHASES OF SCHISTOSOMA MANSONI GRANULOMA DEVELOPMENT}

The evolution of the host response to schistosome eggs in experimental animals has been divided in various stages, according to the authors: florid and cicatricial stages (Grimaud 1986); cellular, productive and regressive stages (Junqueira et al. 1986); nonreactive or weakly reactive, exudative-productive, productive (subdivided in early and advanced phases) and involutional stages ( $\mathrm{Li}$ Hsü et al. 1972).

In patients, the granuloma stages were divided by Coelho (1955) in three stages: first, characterized by focal histolysis and cellular exudation; second, productive or encysted histiocytic reaction, and third, repair or healing, with fibrous substitution, forming a collagenous nodule. On the other hand, Raso and Bogliolo (1970) considered the following stages in the evolution of human schistosomal granulomas: necrotic-exudative, exudative, productive and cure by fibrosis. We propose here a little modification of the Li-Hsü et al. (1972) classification, dividing the maturative and involutional stages of murine $S$. mansoni granuloma in the following stages:

I. Pre-granulomatous stages

I.A. weakly and/or initial reactive (IR) (Fig. 1)

I.B. exudative (E) (Fig. 2)

II. Granulomatous stages

II.A. exudative-productive (EP) (Fig. 3)

II.B. productive $(\mathrm{P})$ (with early and advanced or fibrotic (Fig. 4) phases (PF)

II.C. involutional (I), subdivided in the follow ing subtypes:

II.C.a. with dissociation (and disintegration) of the collagen fibers (Fig. 5)

II.C.b. with thick collagen layer (Fig. 6)

II.C.c. with thin collagen layer (Fig. 7)

II.C.d. pigmented macrophagic type (Fig. 8).

The modification of Li-Hsü et al. (1972) classification was founded on conceptual basis, i.e., the weakly/initial reactive (Figs 1, 9-11) and exuda- tive stages (Figs 2, 12,13) do not fit to the fundamental requirement of the granuloma concept: they are not chronic inflammatory reaction; they do not constitute compact or organized collection of monocyte/macrophage. It should be emphasized that epithelioid cells, which are secretory modified macrophages with large areas of Golgi, a rich display of rough endoplasmic reticulum, and little or no phagocytic potential, is not an absolute requirement to the diagnosis of schistosomal granuloma. Actually this type of granuloma, according to the Hirsh and Johnson (1984) concept, is not a pure epithelioid, but a mixed type of granulomatous inflammation, where the epithelioid cells can or can not be present.

In murine $S$. mansoni granulomas, the giant cells are of two types: one appears randomly, usually located far from the eggs, showing cytoplasm rich in schistosomal pigment (pigmented giant cells); the second type of giant cells are dominant and lay on the top of the egg shells or are egg scavengers, appearing more in the productive and involutional stages of the granulomas (foreign- bodytype giant cells and, rarely, Langhans' giant cells). Usually epithelioid and giant cells in hepatic, intestinal and pancreatic granulomas first appear around 45 to 55 days being more constant from 80 to 100 days after infection.

The pre-granulomatous exudative stage (Figs $2,12,13$ ) is very important in the pathogenesis of the schistosomal infection, causing histolysis and microthrombosis, specially in the liver, and taking part in the "metastatic capability" of the S. mansoni eggs to cross the vessels, allowing them to settle in the justa-vascular tissues (Lenzi et al. 1991). It also participates in the parasite host co-evolution, operating upon parasite transmission, favoring the egg release to the feces (Lenzi et al. 1987, 1997).

To better study the early phase of cellular influx to the eggs we have used the air pouch model in Swiss Webster mice, prepared as described by Edwards et al. (1981) with modifications (Pacheco \& Lenzi, unpub. data). After injection of S. mansoni purified eggs in endotoxin-free saline, in the air pouch, the cells were collected at $4,6,8,12,24,36$, 48, 72 and $96 \mathrm{hr}$ and were counted in Neubauer and Fuchs-Rosenthal chambers and in cyto-centrifuged slides. After stimulus, the absolute number of neutrophils, monocytes/macrophages, eosinophils and lymphocytes predominated, in that order, and reached higher values at 6-8 $\mathrm{hr}$, decreasing steadily with normalization after $36-48 \mathrm{hr}$. We showed that TNF-a, ICAM-1 and CD18 took part in this process, which should be considered as an inflammatory and non-immune event. Then the $S$. mansoni eggs induced early inflammatory reactions that preceeded the granuloma formation. This pre-granu- 

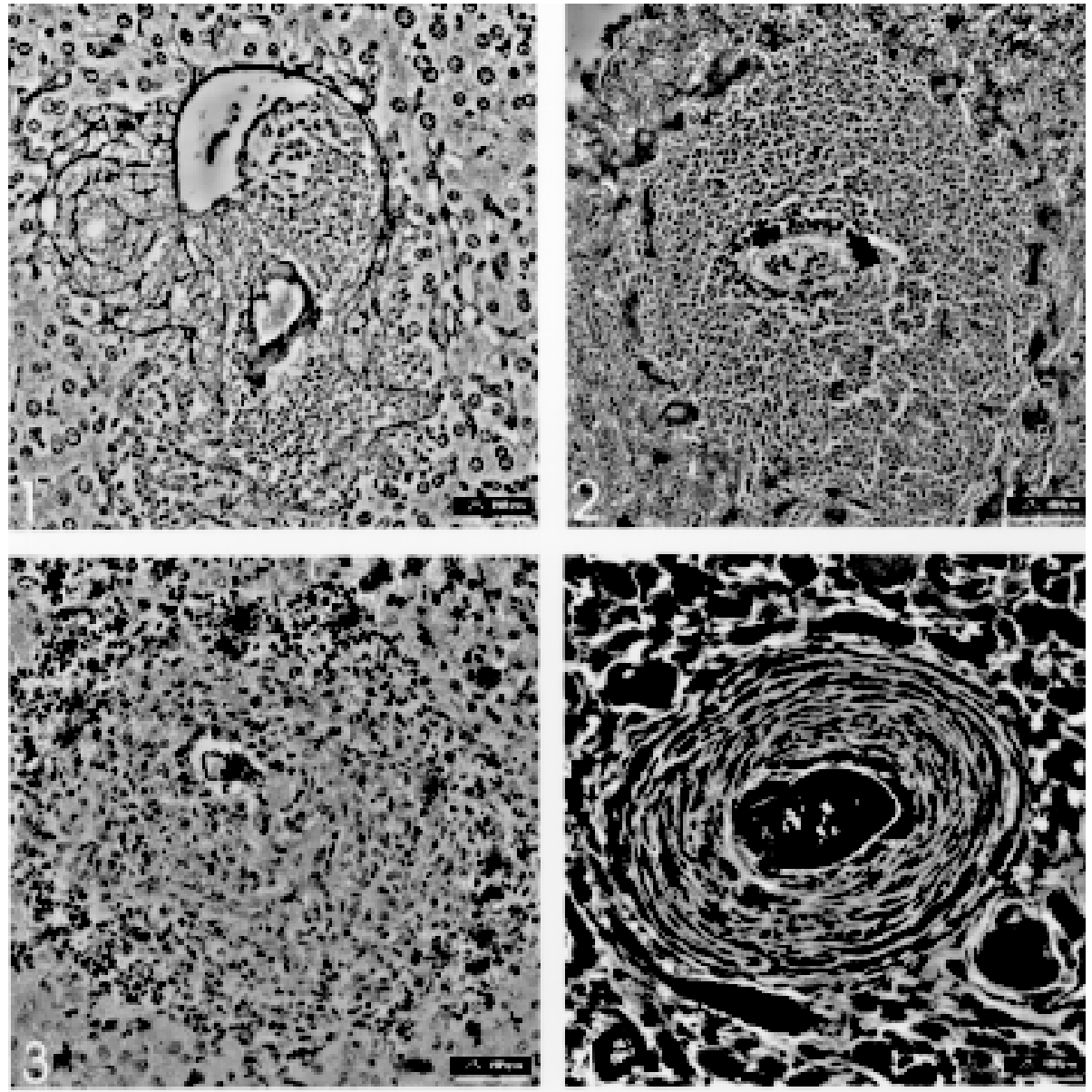

Fig. 1: egg in a portal vein surrounded by a eosinophil and monocyte cushion, which touches and focally invade the vein wall (Gomori's reticulin, bar $=25 \mathrm{~mm}$ ). Fig. 2: exudative granuloma rich in eosinophils and monocytes (these cells were characterized by Giemsa stain), surrounded by a layer of necrotic hepatocytes (Gomori's reticulin stain, bar $=25 \mathrm{~mm}$ ). Fig. 3: exudative-productive granuloma showing dark spots in the peripheral zone that correspond to small aggregates of endothelial cells labelled with anti-factor VIII-related antigen. The slide was counterstained with Mayer's hematoxylin (PAP, bar $=25 \mathrm{~mm}$ ). Fig. 4: productive-fibrotic granuloma showing concentric disposition of collagen fibers in the paracentral layer, stained with phosphomolibdic acid-picrosirius and read by confocal laser scanning microscopy. The external and internal layers almost disappeared (bar $=25 \mathrm{~mm})$.

lomatous phase is not very well studied and probably takes part in the definition of the infection outcome. It represents an antique memory resulted from millenary experience between $S$. mansoni and the hosts, that preceded the beginning of the lymphoid system (Lenzi et al. 1997).

In recent years, a growing body of evidence shows that neutrophils, eosinophils, and not only monocytes/macrophages can synthesize and release a range of immunoregulatory cytokines. Beyond the classical cytokines, like IL-1, TNF and others, monocyte/macrophage lineage expresses two calcium binding proteins: migration inhibitory factor-related proteins 8 and 14 (MRP-8 and MRP14), which belong to the S-100 family of proteins (Kligman \& Hilt 1988). These proteins are also expressed by neutrophils and they are linked with paracrine mechanisms of growth inhibition, antibacterial activity, leukocyte migration, and a role in the pathogenesis of inflammation (Hessian et al. 1993). It has recently been demonstrated that MRP-14, secreted by epithelioid cells from mouse foreign-body granuloma, deactivates activated macrophages in vitro (Aguiar-Passeti 1998). Based 

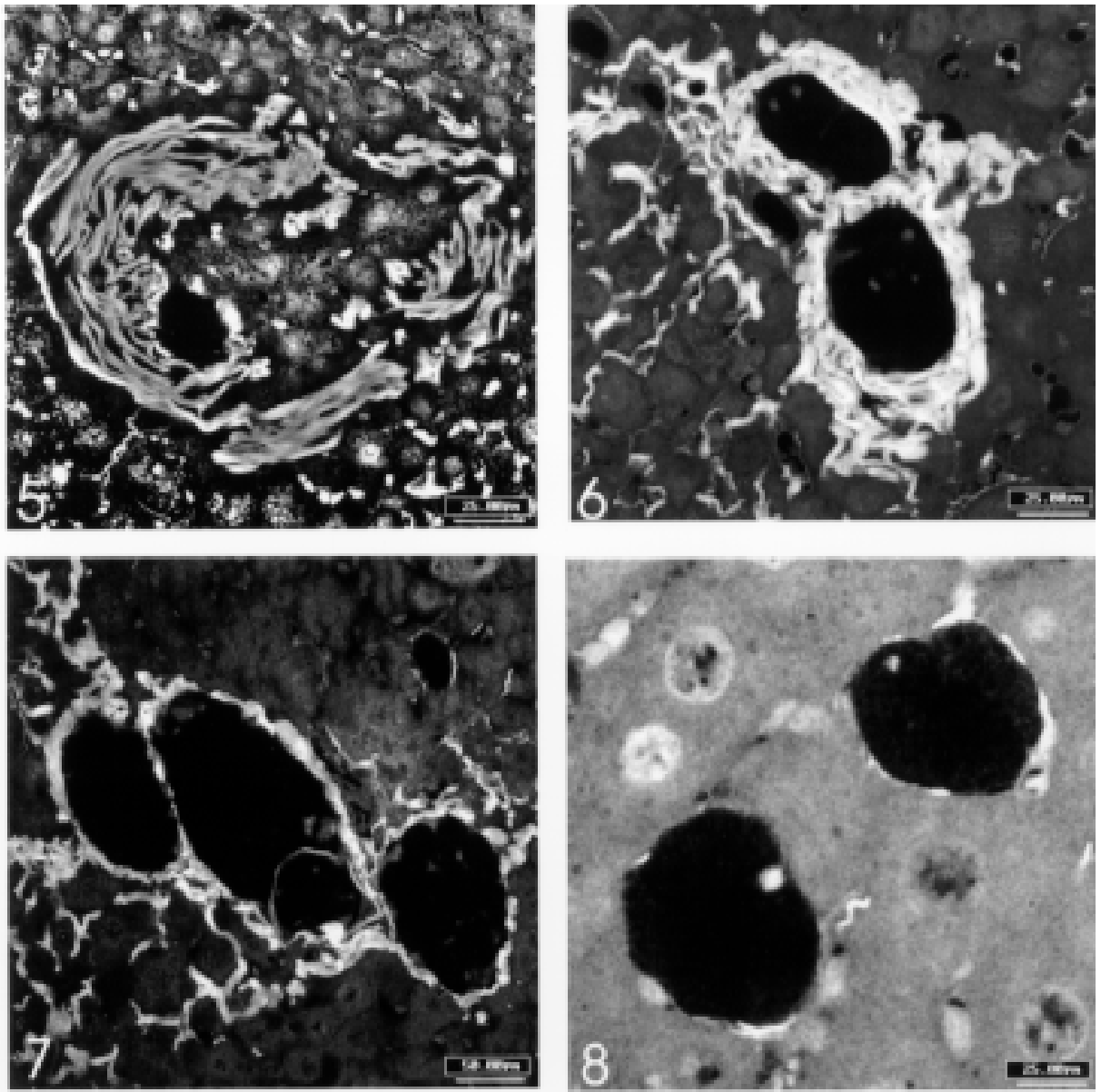

Fig. 5: involutional granuloma with dissociation and disintegration of the collagen fibers, mainly in the right side of the picture (phosphomolibdic acid-picrosirius, confocal laser scanning microscopy, bar $=25 \mathrm{~mm}$ ). Fig. 6: two involutional granulomas with thick collagen layer, surrounding internal zone composed by pigmented macrophages (the macrophages are not seen in this stain) (phosphomolibdic acid-picrosirius, confocal laser scanning microscopy, bar $=25 \mathrm{~mm}$ ). Fig. 7: three involutional granulomas, with thin collagen layer in the periphery. Residual egg shell is seen in the central granuloma (phosphomolibdic acid-picrosirius, confocal laser scanning microscopy, bar $=50 \mathrm{~mm}$ ). Fig. 8: two involutional pigmented macrophagic granulomas showing only fragments of residual collagen fibers in the periphery (phosphomolibdic acid-picrosirius, confocal laser scanning microscopy, bar $=25 \mathrm{~mm}$ ).

on this finding, it was hypothesized that, by deactivating activated cells which migrate to the lesion, MRP-14 could contribute to the persistence of the lesion. Neutrophils can also produce interleukin 1b (IL-1b), tumor necrosis factor a (TNF-a), granulocyte-macrophage colony-stimulating factor (GM-CSF), macrophage colony-stimulating factor (M-CSF), interleukin 6 (IL-6), interleukin 8 (IL-8) and interleukin 1 receptor antagonist (IL-1 ra) (review by Lloyd \& Oppenheim 1992).

Otherwise, there are two principal areas in which recent evidence has suggested collaborative roles for eosinophils: (i) eosinophils as cytokine ("eokine")-producing cells (IL-1a, IL-3, IL-5, IL6, IL-8, GM-CSF, TGF-a, TGF-b, TNF-a, MIP-a (review by Hammann 1995); and (ii) eosinophils as antigen-presenting cells. Functional antigen presentation by eosinophils has been demonstrated for both murine and human cells. Blood eosinophils cultured with GM-CSF to induce HLA-DR and then exposed to tetanus toxoid antigen stimulated proliferation of autologous lymphocytes (Weller 

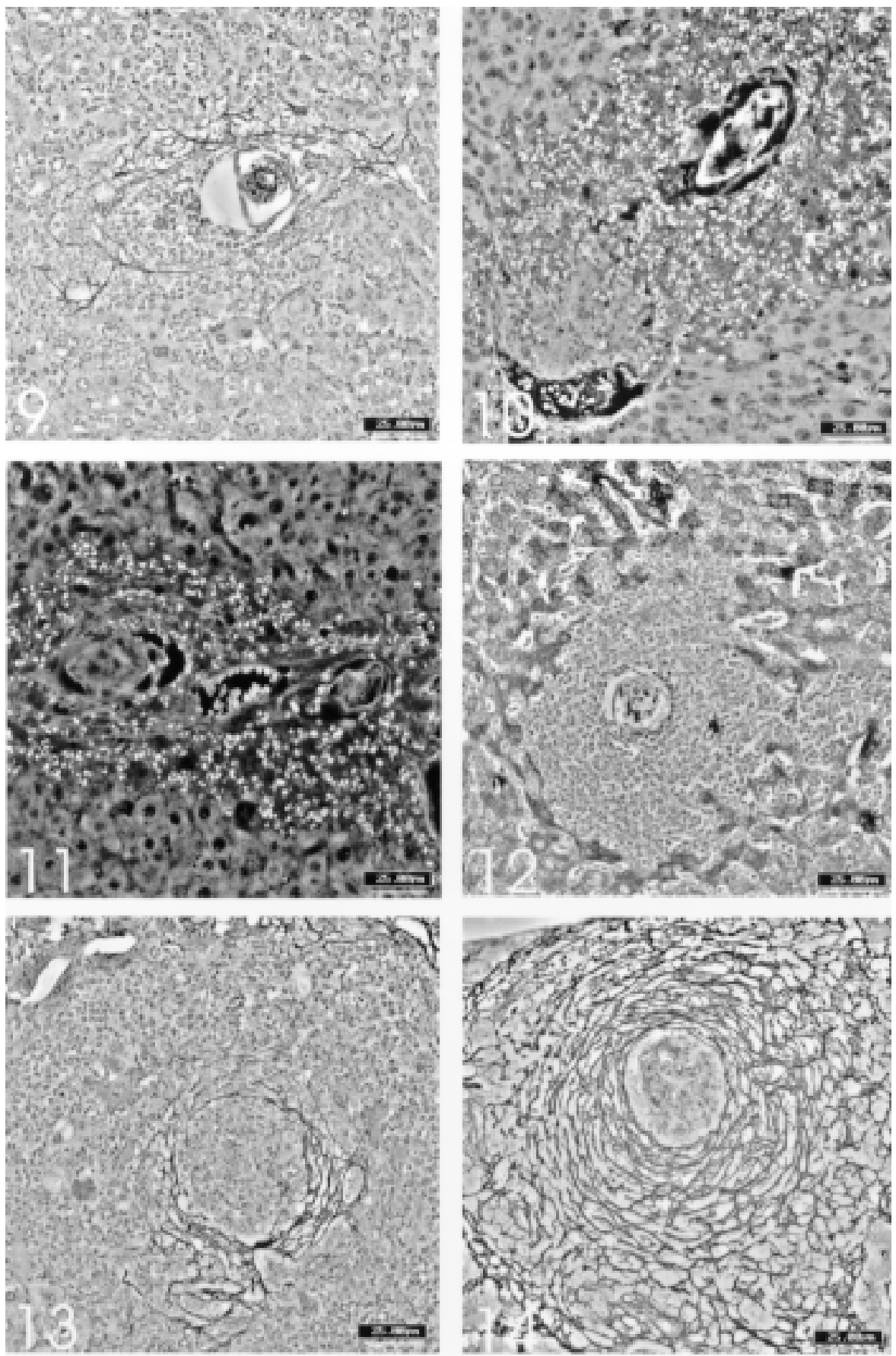

Fig. 9: egg trapped in a portal vein, partially involved by intravascular cells, which permeate the vascular wall, causing dissociation of collagen fibers and forming a perivascular sheath (Gomori's reticulin stain, bar $=25 \mathrm{~mm}$ ). Figs 10, 11: same situation exemplified in Fig. 9, showing a large number of eosinophils in initial exudative periovular reaction. In Fig. 10 appears a thrombus close to the egg (Sirius Red $\mathrm{pH}=10.2$, confocal laser scanning microscopy, bars $=25 \mathrm{~mm}$ ). Fig. 12: initial exudative pre-granulomatous lesion showing the periphery in contact with intrasinusoidal rows of cells (centripetal direction) (Gomori's reticulin stain, bar $=25$ $\mathrm{mm}$ ). Fig. 13: large exudative pre-granulomatous lesion presenting the internal or intravascular and the large peripheral layers intermediated by incipient paracentral layer, originated in the involved intragranulomatous vascular segment. The collagen deposition presents a centrifugal direction, beginning under the original endothelial layer (Gomori's reticulin, bar $=25 \mathrm{~mm}$ ). Fig. 14 : exudative-productive granuloma with the three layers very well defined, showing paracentral layer with concentric disposition (centrifugal decrescent gradient) and peripheral layer with arrangement in mesh (Gomori's reticulin stain, bar $=25 \mathrm{~mm}$ ). 
et al. 1991). These aspects provide strong support for the participation of acute cellular components within T-cell networks during inflammation, and may be relevant to inflammatory-cell interactions in the granuloma process.

A summary about semi-quantitative participation of some cellular and extracellular matrix components, during maturation and involution of $S$. Webster hepatic schistosomal granulomas are presented in the Table.

\section{HISTOARCHITECTURE OF THE SCHISTOSOMAL GRANULOMA}

In the exudative pre-granulomatous stages there is focal destruction of the involved vessel walls and/or adjacent parenchyma (Figs 1, 9-11). The anatomical scaffold of extracellular matrix of the involved tissue is generally completely destroyed, but scarce residual fibers remain, which are mainly of vascular origin. The murine peri-ovular reaction may occur inside or outside the vessels, as was also observed in human cases (Raso \& Bogliolo 1970), and in the Calomys callosus model (Lenzi JA et al. 1995). As infection goes on, little by little, a random reticular scaffold or mesh (see Table, Fig. 15) intermingled with the cells begins to appear, which later on intensifies, presenting trellis-like, or storiform (Fig. 16), or concentric (Figs 14, 17, 18 ), or sometimes radial arrangements, defining clear zones inside the exudative-productive and productive granulomas: inner or internal or paucifibrillar zone, which consists of macrophages, with or without epithelioid transformation and occasionally giant cells; the middle or paracentral zone, rich in fibroblasts (and myofibroblasts?) with or without mast cells and the outmost or external zone, which, depending on the time of infection, presents exuberant extramedullary hematopoiesis (Fig. 18) and, in the more chronic phase of the infection, is rich in lymphocytes (T and B) and plasma cells. The perigranulomatous hematopoiesis is a property of liver granulomas, appearing rarely in pulmonary granulomas, being absent in other places (spleen, intestines, pancreas, etc.) and varies in intensity depending on the mouse strain.

\section{HEMODYNAMIC REPERCUSSIONS OF THE GRANULOMA IN LIVER PARENCHYMA}

Bloch et al. (1972), using video-microscopy to study living liver in mice infected with $S$. mansoni, defined the functional unit of the liver, i.e., the smallest mass of tissue which contains all the structures that participate in the functions of the organ. The unit, which is not the liver lobule, consists of a mass of tissue whose axis is the center of any sinusoid that joins an interlobular portal venule and a central or sublobular venule. The volume of the unit is delimited by a radius extending from the center of such a sinusoid, to the center of the immediately adjacent hepatic cells. Thus a mass of hepatic tissue is delimited whose radius consists of a sinusoid with half of a hepatic cell on every side of the vessel. The length of the unit is a cylinder. The volume of such a unit in mice is approximately $158,200 \mathrm{~m}^{3}$. The unit may, at its origin, be joined by an arterio-sinus twig, the terminal portion of the hepatic arterial system. Bloch et al. (1972) observed that the eggs used to lodge in terminal segments of interlobular portal venules, and each egg was able to obstruct the blood flow of 10 to 20 functional units. Five weeks after the onset of the infection with 20 cercariae, which were subcutaneously injected, 830 functional units could have been involved, while 176,230 and 273,600 might have been involved at the 10th and 20th weeks respectively. Assuming that the mouse liver contains approximately $4.5 \times 10^{6}$ functional units, at the 20th week of the infection the maximum effect that would have been produced solely by eggs would have involved about $6 \%(273,600)$ of the total number of units. These authors observed that ligation of the hepatic artery stopped blood flow in the vessels of the granuloma and adjacent sinusoids, within 1 to $2 \mathrm{sec}$, and also in interlobular portal venules and in central and sublobular venules. This predominance of arterial supply in livers that suffer schistosomal embolization was also showed by Andrade and Cheever (1971). They studied the post-vital vascular system in human livers infected with $S$. mansoni and found a marked increase in the number and size of the intrahepatic arterial branches, which was more pronounced in those areas in the liver where the portal branches were obliterated.

However, there is an intriguing question: why during the pre-granulomatous exudative phase of the periovular region, which is characterized by micro-abscess formation, with frequent vascular destruction, there is no hemorrhage inside the periovular reaction? One possible explanation for this event is the production of local Thromboxane A2 (TxA2) by the periovular cells, as observed by Tripp et al. (1988). The TxA2 is a potent vasoconstrictor, which may contribute to decrease of the granuloma vascularization, resulting in confinement of the egg antigens. Another explanation can be the occurrence of endothelial cell aggregation, by unknown mechanisms, in sinusoid ends, that touch or are nearby the periovular reaction, as shown by Lenzi et al. (1988) (Fig. 3).

\section{BIOMECHANICAL ASPECTS OF THE SCHISTO- SOMAL GRANULOMA}

The collagen network of the granulomas might develop in two main patterns. It might develop first at random and then reoriented following the direc- 
TABLE

Sequencial composition of murine hepatic granulomas during Schistosoma mansoni infection

\begin{tabular}{|c|c|c|c|c|c|c|c|c|c|c|c|c|c|c|c|}
\hline $\begin{array}{l}\text { Time of infection (days) } \\
\text { Type of periovular reaction }\end{array}$ & 25 & $\begin{array}{l}30 \\
\text { IR }\end{array}$ & $\begin{array}{l}35 \\
\mathrm{E}\end{array}$ & $\begin{array}{c}40 \\
\mathrm{E} / \\
\mathrm{EPt}\end{array}$ & $\begin{array}{l}45 \\
\mathrm{EP}\end{array}$ & $\begin{array}{l}50 \\
\mathrm{EP}\end{array}$ & $\begin{array}{l}55 \\
\mathrm{EP}\end{array}$ & $\begin{array}{l}60 \\
\mathrm{EP}\end{array}$ & $\begin{array}{c}70 \\
\mathrm{EP} / \\
\mathrm{P} \\
\end{array}$ & $\begin{array}{c}80 \\
\mathrm{EP} / \\
\mathrm{P}\end{array}$ & $\begin{array}{c}90 \\
\mathrm{EP} / \\
\mathrm{PF} / \mathrm{I}\end{array}$ & $\begin{array}{l}100 \\
\mathrm{EP} / \\
\mathrm{PF}\end{array}$ & $\begin{array}{l}110 \\
\mathrm{EP} / \\
\mathrm{PF}\end{array}$ & $\begin{array}{l}120 \\
\mathrm{EP} / \\
\mathrm{PF} / \mathrm{I} \\
\end{array}$ & $\begin{array}{l}160 \\
\mathrm{EP} / \\
\mathrm{PF} / \mathrm{I} \\
\end{array}$ \\
\hline Macrophages & - & ++ & +++ & +++ & +++ & +++ & +++ & +++ & +++ & +++ & +++ & ++ & ++ & ++ & ++ \\
\hline Epithelioid cells & - & - & - & - & $+/-$ & + & + & + & + & + & + & + & + & + & + \\
\hline Giant cells & - & - & - & $+/-$ & $+/-$ & $+/-$ & $+/-$ & $+/-$ & $+/-$ & $+/-$ & + & + & + & + & ++ \\
\hline Neutrphils & - & - & - & $+/-$ & $+/-$ & + & ++ & + & + & + & + & + & $+/-$ & + & ++ \\
\hline Eosinophils & - & ++ & +++ & +++ & +++ & +++ & +++ & +++ & +++ & +++ & +++ & ++ & ++ & ++ & ++ \\
\hline Mast cells & - & - & - & + & + & ++ & + & $+/-$ & $+/-$ & ++ & + & + & + & + & + \\
\hline "Fibroblasts" & - & - & - & + & + & + & + & + & + & ++ & ++ & +++ & ++ & ++ & ++ \\
\hline Lymphocytes & - & - & - & + & + & + & + & + & + & + & + & + & + & + & + \\
\hline Plasma cells & - & - & - & + & + & + & ++ & + & ++ & ++ & ++ & ++ & ++ & ++ & ++ \\
\hline Reticular fibers & - & - & - & $+\mathrm{M}$ & $+\mathrm{MCo}$ & $+\mathrm{CoM}$ & $+\mathrm{CoM}$ & $+\mathrm{CoM}$ & $+\mathrm{Co}$ & $+\mathrm{Co}$ & $+\mathrm{Co}$ & $+\mathrm{Co}$ & $+\mathrm{Co}$ & $+\mathrm{Co}$ & $+\mathrm{Co}$ \\
\hline PAS & - & - & - & + & + & $+/-$ & $+/-$ & $+/-$ & $+/-$ & ++ & - & + & $+/-$ & + & + \\
\hline Alcian blue $\mathrm{pH} 1.0$ & - & - & - & ++ & + & + & + & + & + & ++ & ++ & ++ & + & + & ++ \\
\hline Alcian blue $\mathrm{pH} 2.5$ & - & - & - & + & $+/-$ & + & + & ++ & ++ & +++ & +++ & ++ & ++ & ++ & $+/-$ \\
\hline Pigment & - & - & - & $+\mathrm{D}$ & $+\mathrm{D}$ & $+\mathrm{Pe}$ & $+\mathrm{Pe}$ & $+\mathrm{Pe}$ & $++\mathrm{Pe}$ & $+\mathrm{Pe}$ & $++\mathrm{Pe}$ & $++\mathrm{Pe}$ & $++\mathrm{Pe}$ & $++\mathrm{Pe}$ & $+\mathrm{Pe}$ \\
\hline
\end{tabular}

IR: initial reactive; E: exudative; EP: exudative-productive; P: productive; PF: productive-fibrotic; I: involutional; T: transitional; M: mesh disposition; Co: concentric disposition;

D: diffuse; Pe: peripheral; (-): negative; (+/- to +++): increasing levels of intensity. 

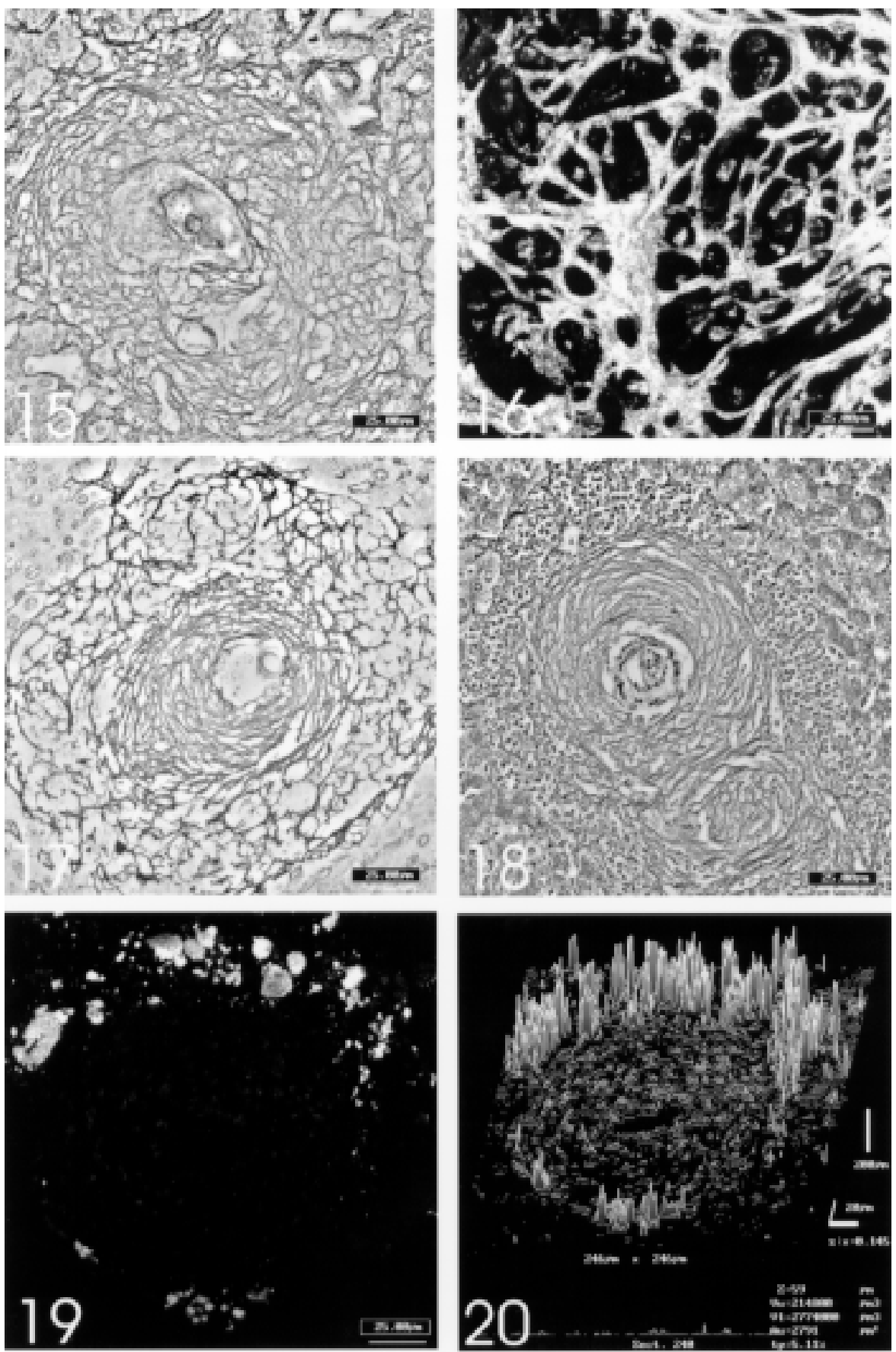

Figs 15, 16: exudative-productive granuloma with the fibers of the paracentral layer forming a mesh, with points of anchorage. These points are detailed in the Fig. 16 (Fig. 15: Gomori's reticulin; Fig. 16: periodic acid methanamine silver, confocal laser scanning microscopy, bars $=25 \mathrm{~mm}$ ). Figs 17, 18: exudative-productive granulomas showing a prominent external or peripheral layer due to myeloid metaplasia. The stroma in the metaplasic area forms a network of reticular fibers. The paracentral zone shows accentuated concentricity of the fibers (Gomori's reticulin, bars $=25 \mathrm{~mm}$ ). Fig. 19: large macrophages full of schistosomal pigment, analyzed by reflected laser $(\mathrm{He} / \mathrm{Ne} 633 \mathrm{~nm}$ ) (confocal laser scanning microscopy, bar $=25 \mathrm{~mm}$ ). Fig. 20: histogram of the Fig. 19, showing the peaks that correspond to presence of the pigmented macrophages (confocal laser scanning microscopy). 
tion of the mechanical stresses. Another possible pattern is when the fibers develop in a preferred direction according to the stress. The role of the collagen structure might be the protection of the sealing cellular envelope, reinforcing it against any kind of mechanical impairment such as a sudden rise of the internal pressure. On the other hand, its role might be just to hold in place the enclosing tissues of the new organoid structure. In fact, the huge amount of extracellular matrix (ECM) production by the granuloma cells, not dependent on surrounding pressure forces (data not published), emphasizes more the biological than the mechanical role of the ECM molecules on the granuloma histogenesis.

We suggest a model for the development of granulomas, according to the following stages: (1) encapsulating (EN); (2) focal histolysis (FH); (3) fiber production (FP); (4) orientation and compacting (OC), and (5) involution and disintegration (ID). First, during few days, the egg is trapped in a vein of about its size. Then, a very quick process occurs when many cells such as monocytes and eosinophils, with a few lymphocytes, make a cellular cushion around the egg (EN) (Figs 1, 9-11). Some cells form bridges from the egg to the endothelium, and then penetrate through the vessel wall, creating a small perivenular sheath (Figs 1, 9-11), and later on, the number of infiltrating cells increase and intensely diffuse to the perivascular tissue (outward cellular wave of FH), and together with cells that are chemo-attracted from the sinusoids (liver) or other adjacent vessels (inward cellular wave of $\mathrm{FH}$ ), form a loose cluster of many exudative cells with dimensions that can reach up to five times the size of the egg, while pushing the wall fibers away (Figs 12, 13). These exudative aggregate of cells occupies the space caused by focal histolysis. Next, the paracentral layer is built, rich in fibroblasts and myofibroblasts from the original vessel wall, and new collagen fibers (FP) (Figs 13,14). The build up of the fibrous mesh of the paracentral layer starts usually from innermost part of the residual vascular wall, in the interface between the internal layer and the beginning of the paracentral layer, proceeding toward the outside (centrifugal direction) (Figs 13, 14). But this is not the only mode of development. In the case of the egg trapped in a portal space, fibers are produced over a huge area, all at about the same time and faster, namely the FP process might start early during EN stage. In some cases, the build up starts near the egg and the development is outwards. Simultaneously, scattered fibers are generated in an external layer. The fibers of the paracentral layer are not stretched and are oriented in all directions at random at this stage - the early stage of the exu- dative/productive phase. The mesh has some order in the form of a star-shape nodal points, which might be associated with fiber production sites (Figs 15, 16). If the granuloma would have been formed in a zone of stressed tissue, the fibers would take, from the start, a preferred orientation parallel to the direction of stretching of the tissue. Granulomas, in general, start to develop in non stressed tissues such as small venules in the liver. Radial orientation and/or mesh-like pattern of reticular fibers are usually seen in external layer, expanded by active hematopoietic metaplasia (Figs 14, 17, 18) where is common to see pigmented macrophages (Figs 19, 20). Only in few cases, radial orientation of fibers is observed in pulmonary granulomas, which might be associated with radial stretching forces acting upon the granuloma. In a later stage of the exudative-productive phase, the fibrous mesh of the paracentral layer becomes more compact, parallel and concentric, acquiring a circumferential arrangement (OC) (Figs 4, 17, 18). In very few cases the internal layer of the granuloma continues to grow against the fibrous structure of the paracentral layer, and may press from inside outwards, causing circumferential stretching stresses in the central layer. The collagen fibers then would be stretched and reoriented slowly until they would take the concentric form around the egg. After the spontaneous death of the miracidia (Reis \& Andrade 1987), the internal layer shrinks, while the paracentral layer is then pushed inwards, due to the pressure from the surrounding tissues. Inflammation subsides, maintaining almost only pigmented macrophages, and degradation of extracellular matrix begin to predominate over ECM formation, tending to reestablish a normal or nearnormal stroma/parenchyma ratio (Figs 5-8) (Andrade \& Grimaud 1986, 1988, Andrade 1989, 1992) (ID). At the end of ID stage, the granuloma disappears.

\section{DISCUSSION}

The schistosomal granuloma is an organoid, dynamic and hybrid structure, formed by host and egg components, interacting in a synergistic process where the function of the fully formed structure is literally greater than the sum of the actions of its individual cells, extracellular matrix material and egg products. Probably, it represents an evolutionary novelty that works like an interface between living beings in search of symbiosis. The morphogenesis of the granuloma is build up by ancient mechanisms performed namely by phagocytic cells. The schistosomal granuloma, imitating some organogenesis process, has a maturation and an involutional phase. These phases from the morphological point of view are expressed by a 
pre-granulomatous and a granulomatous stage. The former has a lytic character, which prepares the space through destruction of the parenchyma to the establishment and organization of the later one (granulomatous stage). In the granulomatous stage, cellular adhesion and sorting play an important role. Various types of cells exhibit different degrees of adhesion, mainly heterotypic (data not shown). Cells, influenced by chemical and biomechanical forces, arrange themselves into specific patterns, including the sorting out of different types of cells from each other. The effects of aggregation and sorting create different zones in the granuloma structure, where the combination of different types of cells consistently form an internal layer (periovular), enveloped by the paracentral and external layers. Probably the cells with stronger mutual adhesion aggregate in the center, whereas cells with weaker attraction remain at the surface, creating a differential cellular adhesiveness. Cells appear to migrate from the less adhesive (external layer) to the more adhesive layer (internal layer) through an adhesive gradient (haptotaxis) provoked by egg products. The ECM presents, during the maturation and involutional phases of the granuloma, three basic patterns: provisional (rich mainly in fibronectin); quasi-definitive (predominantly collagenic) and involutional (degradation or ECMlysis predominate over synthesis or ECM-genesis). The tissue architecture of the granuloma ECM-fibers are initially arranged in a mesh pattern, evolving to a final and compact concentric arrangement. Probably the pattern of the three-dimensional structure of the granuloma matrix has a particularly strong influence on the phenotype of the cells, mainly of the fibroblasts and myofibroblasts as observed in wound repair (Gailit \& Clark 1994). Although it is not widely appreciated, the fibroblast phenotype changes radically during wound repair (Welch et al. 1990). Fibroblast could initially differentiate into myofibroblast and in a second step get on a form of programmed cell death triggered by contraction of the collagen matrix (Lin \& Grinnell 1993) presenting evidence that mechanical interactions between cells and their surrounding matrix can modulate the autophosphorylation of growth factor receptors. Although the mechanism for this modulation is not known, it could play a significant part in tempering the effects of cytokines during the maturation and involutional stages of the granuloma. These observations add new insights to interpret the granuloma modulation and involution. In conclusion, schistosomal granuloma is not a tangled web of individual cells and fibers, but an organized structure composed by host and parasite components, which is not formed to attack the miracidia, but functions as an hybrid interface between two different phylogenetic beings. Indeed, findings of Reis and Andrade (1987) indicate that the periovular granuloma occurring in schistosomiasis probably serves to protect the host tissues from the miracidial secretions rather than to attack and kill the miracidium as suggested by previous studies.

\section{ACKNOWLEDGEMENTS}

To AL de Amorim, FF Cruz, ID Pedro and LFG Caputo for their expert technical assistance.

\section{REFERENCES}

Adams DO 1976. The granulomatous inflammatory response. Am J Pathol 84: 165-191.

Adams DO 1983. The biology of the granuloma, p. 120. In HL Ioachim, Pathology of Granulomas, Raven Press, New York.

Aguiar-Passeti T 1998. Células Epitelióides de Granuloma Induzido por Corpo Estranho Expressam Seletivamente a Proteína Ligante de Cálcio MRP14, uma Molécula Inibitória da Ativação de Macrófagos, PhD Thesis, Instituto de Ciências Biomédicas, Universidade de São Paulo, São Paulo, $87 \mathrm{pp}$.

Andrade ZA 1989. Evolution and involution of hepatosplenic schistosomiasis. Mem Inst Oswaldo Cruz 84 (Suppl. I): 58-75.

Andrade ZA 1992. Morphological features of collagen degradation in advanced hepatic schistosomiasis of man. Mem Inst Oswaldo Cruz 87 (Suppl. IV): 129138.

Andrade ZA, Cheever AW 1971. Alterations of the intrahepatic vasculature in hepatosplenic schistosomiasis mansoni. Am J Trop Med Hyg 20: 425-432.

Andrade ZA, Grimaud JA 1986. Evolution of the schistosomal hepatic lesions in mice after curative chemotherapy. Am J Pathol 124: 59-65.

Andrade ZA, Grimaud JA 1988. Morphology of chronic collagen resorption. A study on the late stages of schistosomal granuloma involution. Am J Pathol 132: 389-399.

Bloch EH, Abdel-Wahab MF, Warren KS 1972. In vivo microscopic observations of the pathogenesis and pathophysiology of hepatosplenic schistosomiasis in the mouse liver. Am J Trop Med Hyg II: 546-557.

Boros DL 1978. Granulomatous inflammations. Prog Allergy 24: 183-267.

Cameron GR, Gangully NC 1964. An experimental study of the pathogenesis and reversibility of schistosomal hepatic fibrosis. J Pathol Bact 87: 217-237.

Coelho RB 1955. Patologia da esquistossomose mansônica. 1. Comportamento do ôvo do Schistosoma mansoni. Publ Avulsas do Inst Aggeu Magalhães 4: 61-71.

De Britto T, Franco MF 1994. Granulomatous inflammation. Rev Inst Med Trop São Paulo 36: 185-192.

Edwards J, Sedgwick A, Willoughby D 1981. The formation of a structure with the features of synovial lining by subcutaneous injection of air: an in vivo tissue culture system. J Pathol 134: 147-156. 
Epstein WL 1977. Granuloma formation in man. Pathobiol Annu 7: 1-30.

Epstein WL 1983. Granulomatous inflammation in skin, p. 21-59. In HL Ioachim, Pathology of Granulomas, Raven Press, New York.

Gailit J, Clark RAF 1994. Wound repair in the context of extracellular matrix. Current Biol 6: 717-725.

Grimaud JA 1986. Myofibroblastes et cellules collaboratrices: les cellules clés des interactions cellule-matrice conjonctive dans l'évolution du granulome hépatique de la bilharziose à Schistosoma mansoni. Arch Anat Cytol Path 34: 30-31.

Hamann KJ 1995. Eosinophil mediators, p. 298-327. In WW Busse, ST Holgate (eds), Asthma and Rhinitis, Blackwell Scientific Publications, Oxford.

Hessian PA, Edgeworth J, Hogg N 1993. MRP-8 and MRP-14, two abundant $\mathrm{Ca}^{2+}$ binding proteins of neutrophils and monocytes. J Leuk Biol 53: 197-204.

Hirsh BC, Johnson WC 1984. Concepts of granulomatous inflammation. Int J Dermatol 23: 90-100.

Ingber DE 1993. Extracellular matrix and the development of tissue architecture: a mechano-chemical perspective, p. 403-428. In MA Zern, LM Reid (eds), Extracellular Matrix - Chemistry, Biology, and Pathobiology with Emphasis on the Liver, Marcel Dekker Inc., New York.

Junqueira LCU, Montes GS, Toledo OMS, Joazeiro PP 1986. Morphological, histochemical and biochemical observations on the connective tissue matrix of in situ and isolated hepatic granulomas in experimental murine schistosomiasis. Ann Trop Med Parasitol 80: 27-41.

Kligman D, Hilt DC 1988. The S-100 protein family. Trends Biochem Sci 13: 437-443.

Lenzi HL, Lenzi JA, Sobral ACL 1987. Eosinophils favor the passage of eggs to the intestinal lumen in schistosomiasis. Braz J Med Biol Res 20: 433-435.

Lenzi HL, Sobral ACL, Lenzi JA 1988. Participation of endothelial cells in murine schistosomiasis. Braz J Med Biol Res 21: 999-1003.

Lenzi HL, Lenzi JA, Kerr IB, Antunes SLG, Mota EM, Oliveira DN 1991. Extracellular matrix in parasitic and infectious diseases. Mem Inst Oswaldo Cruz 86 (Suppl. III): 77-90.

Lenzi HL, Pacheco RG, Pelajo-Machado M, Panasco MS, Romanha WS, Lenzi JA 1997. Immunological system and Schistosoma mansoni: co-evolutionary immunobiology. What is the eosinophil role in parasite-host relationship? Mem Inst Oswaldo Cruz 92
(Suppl. II): 19-32.

Lenzi JA, Mota EM, Pelajo-Machado M, Paiva RAN, Lenzi HL 1995. Calomys callosus: an alternative model to study fibrosis in schistosomiasis mansoni. The pathology of the acute phase. Mem Inst Oswaldo Cruz 90: 311-318.

Li Hsü SY, Hsü HF, Davis JR, Lust GL 1972. Comparative studies on the lesions caused by eggs of Schistosoma mansoni in livers of albino mice and rhesus monkeys. Ann Trop Med Parasitol 66: 89-97.

Lin YC, Grinnel F 1993. Decreased level of PDGFstimulated receptor autophosphorylation by fibroblasts in mechanically relaxed collagen matrices. $J$ Cell Biol 122: 663-672.

Lloyd AR, Oppenheim JJ 1992. Poly's lament: the neglected role of the polymorphonuclear neutrophil in the afferent limb of the immune response. Immunol Today 13: 169-172.

Mariano M 1995. The experimental granuloma. A hypothesis to explain the persistence of the lesion. Rev Inst Med Trop São Paulo 37: 1-15.

Raso P, Bogliolo L 1970. Patologia, p. 77-130. In AS Cunha, Esquistossomose Mansoni, Editora da Universidade de São Paulo, São Paulo.

Reis MG, Andrade ZA 1987. Functional significance of periovular granuloma in schistosomiasis. Braz J Med Biol Res 20: 55-62.

Tripp CS, Needleman P, Kassab JT, Weinstock JV 1988. Macrophages isolated from liver granulomas of murine Schistosoma mansoni synthesize predominantly TxA2 during the acute and chronic phases of infection. J Immunol 140: 3140-3143.

Turk JL 1992. Granulomatous diseases, p. 394-406. In JOD McGee, PG Isaacson, NA Wright (eds), $O x$ ford Textbook of Pathology, Oxford University Press, Oxford.

Warren KS 1976. A functional classification of granulomatous inflammation. Ann New York Acad Sci 278: 7-18.

Welch MP, Odland GF, Clark RAF 1990. Temporal relationships of F-Actin bundle formation, collagen and fibronectin matrix assembly, and fibronectin receptor expression to wound contraction. J Cell Biol 110: 133-145.

Weller PF, Rand TH, Finberg RW 1991. Human eosinophil function as HLA-DR dependent, MHC-restricted antigen-presenting cells. FASEB J 5: A640.

Williams GT, Williams WJ 1983. Granulomatous inflammation - a review. J Clin Pathol 36: 723-733. 
Histoarchitecture of Schistosomal Granuloma • Henrique L Lenzi et al. 